\title{
Urea incorporated into ordered mesoporous silica for potential cosmetic application
}

\author{
Vânia Rodrigues Leite-Silva, Camila Vieira da Silva, Celio Takashi \\ Higuchi, Heron Dominguez Torres da Silva, Marcelo Dutra Duque, \\ Newton Andréo-Filho, Patrícia Santos Lopes, Tereza Silva Martins ${ }^{(*}$ \\ Instituto de Ciências Ambientais, Químicas e Farmacêuticas, \\ Universidade Federal de São Paulo, Diadema - SP, Brazil
}

\begin{abstract}
Urea's thermal instability and burning on sensitive skin can cause problems for cosmetic formulations. To overcome these drawbacks, urea was incorporated into ordered mesoporous silica (SBA-15). SBA15 was synthesized using tetraethyl orthosilicate and Pluronic ${ }^{\circledR} P 12^{3}$ in an acid medium. Urea (20 wt.\%) was incorporated into calcined SBA-15 by the incipient wetness impregnation method. Several techniques were used to characterize the samples. Skin hydration and transepidermal water loss were measured using Corneometer ${ }^{\circledR}$ CM 825 PC and Tewameter ${ }^{\circledR} 300$ TM. Results showed that the structural properties of SBA-15Urea were similar to pure SBA-15, indicating that SBA-15 remained structured even after urea incorporation. Nitrogen physisorption data showed the volume and surface area of the pores in SBA-15Urea were much lower than those in SBA-15, demonstrating that urea was deposited inside the mesopores. In vivo moisturization studies revealed that SBA-15Urea was not able to reduce transepidermal water loss compared to the other products and control, while forming a non-occlusive surface film on the skin. We conclude that incorporation of urea in the pores of the inorganic SBA-15 matrix is a promising approach to enhancing its stability and providing a prolonged moisturizing effect.
\end{abstract}

KEYWORDS: SBA-15. Urea. Cosmetic active. Post-synthesis. Mesoporous silica.

\section{INTRODUCTION}

Chemical substances with moisturizing properties are widely used as cosmetic actives. These, urea $\left(\mathrm{CO}\left(\mathrm{NH}_{2}\right)_{2}\right)$ is one the most valuable, due to its hydrophilic properties that promote water retention (Kapuscinska, 2014). Urea also known as carbamide is a colorless, odorless solid, highly soluble in water and is a natural constituent of the skin because it is produced by the human body as a result of metabolism of proteins and other compounds containing nitrogen.

*Correspondence: T. S. Martins Departamento de Química Universidade Federal de São Paul. Rua São Nicolau, 210, 2nd floor, 09913-030. Diadema, São Paulo, Brazil. Phone: +55 11 40440500. E-mail addresses: tsmartins@ unifesp.br (Tereza S. Martins*).
It is practically non-toxic ( $\mathrm{LD}_{50}$ is $15 \mathrm{~g} \mathrm{~kg}^{-1}$ for rats) and it acts as a natural moisturizing factor (approximately $7 \mathrm{wt} . \%)$ and the risk of allergic reactions is very low (Decaux et al., 2014; Kapuscinska, 2014). Despite its advantages, however, urea's thermal instability and a possible sensation of tingling or burning on sensitive skin can cause problems for cosmetic formulations mainly when urea is used in high concentration (Kapuscinska, 2014).

Formulations with up to $10 \mathrm{wt} \%$ of urea are considered medicine, due to its keratolytic effects (Harivel, Besse, 2011; Sore, Hansenne, 2004). As urea readily cross the placental barrier, regulatory agencies such as the Food and Drug Administration (FDA), Cosmetic Ingredient Review (CIR) and Canada Health recommend that urea-based cosmetics and medicines 
are not used during pregnancy (Anvisa, 2010; Yamarik et al., 2005). Besides that, its stability decreases with increasing temperature. This is a problem for cosmetic formulations because depending on the reaction medium, temperature and $\mathrm{pH}$ conditions used, urea can be decomposed into ammonia and isocyanic acid (Eq. 1) that react with water by hydrolysis to form ammonia (Eq. 2) (Panyachariwat et al., 2014; Jiao at al., 2016):

$$
\begin{aligned}
& \mathrm{CO}\left(\mathrm{NH}_{2}\right)_{2}(\mathrm{~s}) \rightarrow \mathrm{NH}_{3}(\mathrm{~g})+\mathrm{HNCO}(\mathrm{g}) \\
& \mathrm{HNCO}(\mathrm{g})+\mathrm{H}_{2} \mathrm{O}(\mathrm{g}) \rightarrow \mathrm{NH}_{3}(\mathrm{~g})+\mathrm{CO}_{2}(g)
\end{aligned}
$$

In order to improve the moisturizing action of the urea and its thermal properties, and also prevent skin irritation, the incorporation of urea into an ordered mesoporous silica (OMS) matrix such as SBA-15 (amorphous $\mathrm{SiO}_{2}$ named as Santa Barbara Amorphous-15) can be a good option. We believe that dispersal of urea into these nanopores would lead a gradual urea release from within the pores, with a consequently prolonged hydration action providing unique benefits for a cosmetic product. SBA-15 is a promising candidate due to unique properties, such as high specific surface area (above $700 \mathrm{~m}^{2} \mathrm{~g}^{-1}$ ), pore size around $10 \mathrm{~nm}$ which can be expanded up to $50 \mathrm{~nm}$ with swelling agents, high pore volume (up to $2.5 \mathrm{~cm}^{3} \mathrm{~g}^{-1}$ ) and a hydrophilic surface (Zhao et al., 1998a; Zhao et al., 1998b; Johansson et al., 2010; Pal, Bhaumik, 2013; Vinu et al., 2006; Mody et al., 2013; Alothman, 2012; Jardim et al., 2016).

Ordered mesoporous silica has attracted greatly interest for several applications, mainly for drug delivery and catalysis, and many research groups have been studying them (Jiao et al., 2016; Jardim et al., 2016; Martins et al., 2010; Pérez-Esteve et al., 2016; Braun et al., 2016; Yu et al., 2016; Ayad et al., 2016; Vieira et al. 2019; Takamori, et al. 2019). Most of these studies focused both in vitro and in vivo tests and concluded that these silicas have good thermal and chemical stability and biocompatibility and low toxicity. A variety of chemical modifications have been made to their external and internal surface, according to the need, to make them either hydrophobic or hydrophilic (Ayad et al., 2016; Tarn et al., 2013; da Silva et al., 2006). These are valuable properties for cosmetic applications.

In this work, urea was incorporated into SBA15 by an incipient wetness impregnation method to yield an SBA-15Urea material. Cosmetic formulations containing the characterized material were then used for in vivo studies of skin moisturization. The main aim of this study was to demonstrate improved thermal stability of urea and to promote long-lasting skin hydration by gradual urea release from SBA-15.

\section{MATERIAL AND METHODS}

\section{Material}

Tetraethyl orthosilicate (TEOS), triblock copolymer Pluronic ${ }^{\circledR} \mathrm{P} 123\left(\mathrm{EO}_{20} \mathrm{PO}_{70} \mathrm{EO}_{20}\right)$, hydrochloric acid (ACS reagent, 37\%), ethanol and urea were purchased from Sigma-Aldrich (Missouri, USA) and used as received, without purification; hydroxyethylcellulose and phenoxyethanol were of pharmaceutical grade.

\section{SBA-15 Synthesis}

SBA-15 was synthesized using a procedure reported by Zhao (Zhao et al., 1998b). TEOS was used as silica precursor and Pluronic ${ }^{\circledR} \mathrm{P} 123$ as the structuredirecting agent in an acid medium $\left(\mathrm{HCl}, 2.0 \mathrm{~mol} \mathrm{~L}^{-1}\right)$. $4.0 \mathrm{~g}$ of Pluronic ${ }^{\circledR} \mathrm{P} 123$ were dissolved in $30.0 \mathrm{~g}$ of water and $120.0 \mathrm{~g}$ of $\mathrm{HCl}$ and stirred at room temperature to produce a homogeneous mixture and then $8.32 \mathrm{~g}$ of TEOS was added. The mixture was stirred vigorously at $40{ }^{\circ} \mathrm{C}$ for $24 \mathrm{~h}$ and heated in a Teflon-lined autoclave at $100{ }^{\circ} \mathrm{C}$ for $48 \mathrm{~h}$. The SBA-15 product was separated from the solution by filtration, washed with deionized water, dried at $60{ }^{\circ} \mathrm{C}$ and calcinated at $540{ }^{\circ} \mathrm{C}$ for about $4 \mathrm{~h}$ under a nitrogen atmosphere. Soon after the atmosphere was switched to air, while keeping the furnace temperature at $540{ }^{\circ} \mathrm{C}$ for another three hours.

\section{Preparation of SBA-15Urea}

Urea was incorporated into SBA-15 by incipient wetness impregnation method, according to the following procedure: Urea $(0.38 \mathrm{~g})$ dissolved in ethanol (5.5 $\mathrm{mL})$, was added to SBA-15 (1.5 g) suspended in ethanol $(25.0 \mathrm{~mL})$. The mixture was stirred at room temperature for $48 \mathrm{~h}$. A rotary evaporator was then used to remove solvent. The material obtained was dried under vacuum over anhydrous calcium chloride and the sample was designated as SBA-15Urea. The schematic representation of the synthesis of this material is shown in Figure 1. 


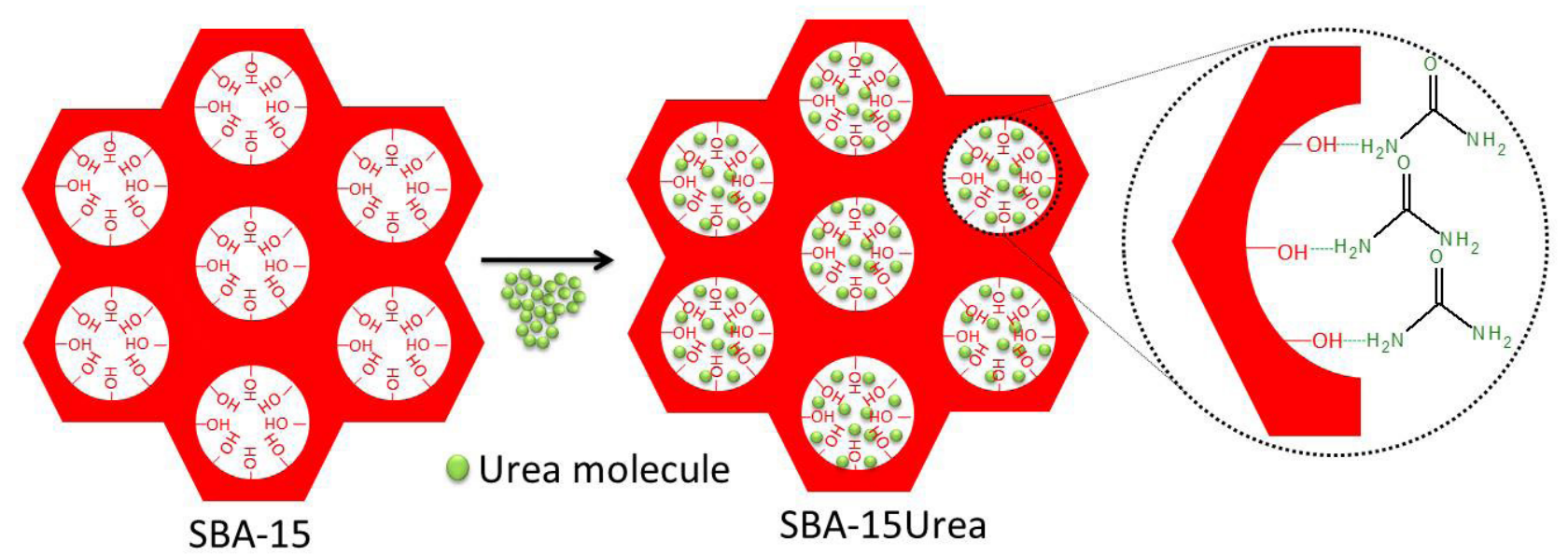

FIGURE 1 - Schematic representation of SBA-15Urea synthesis.

\section{Characterization}

All samples were characterized by small angle X-ray diffractometry (SA-XRD), $\mathrm{N}_{2}$ adsorptiondesorption isotherms (NAI), Fourier transform infrared spectroscopy (FTIR), thermogravimetric analysis (TG) and differential thermal analysis (DTA).

Small angle X-ray diffractometry of the samples was recorded on a Nanostar Bruker diffractometer by using $\mathrm{CuK} \alpha$ radiation $(\lambda=0.15418 \mathrm{~nm})$ operating at $40 \mathrm{kV}$ and $30 \mathrm{~mA}$, with a multivalent Hi-STAR bidimensional detector. The sample to detector distance was $65 \mathrm{~cm}$, with $\mathrm{q}$ vector values ranging from 0.2 to $3.5 \mathrm{~nm}^{1}$. All the data were normalized by measuring time and being corrected for absorption effects.

Nitrogen adsorption-desorption isotherms were performed with a NOVA (Quantachrome) porosimeter. Prior thermal treatment at $60{ }^{\circ} \mathrm{C}$ was made in order to dry the samples and the isotherms were taken at $77 \mathrm{~K}$ $\left(\mathrm{N}_{2}\right)$. The pore size distribution, pore volume and pore radius were calculated using the BJH (Barrett-JoynerHalenda) method (Barret at al., 1951). The surface area was calculated using the BET (Brunauer-Emmett-Teller) method (Brunauer et al., 1938).

Infrared absorption spectra (IR) were recorded in the range $4000-400 \mathrm{~cm}^{-1}$ in $\mathrm{KBr}$ pellets, using an IR Prestige-21 Fourier Transformation (FT) Spectrophotometer, Shimadzu.

Thermogravimetric analysis and differential thermal analysis curves were obtained on a Shimadzu simultaneous TGA/DTA analyzer DTG-60H in the temperature range 25 to $900{ }^{\circ} \mathrm{C}$ with heating rate of $20{ }^{\circ} \mathrm{C} \mathrm{min}{ }^{-1}$, under air atmosphere $\left(100 \mathrm{~cm}^{3} \mathrm{~min}^{-1}\right)$ and using alumina crucibles with approximately $5.0 \mathrm{mg}$ of the sample.

The morphology of SBA-15 was examined by scanning electron microscopy (SEM). The SBA-15 powder directly onto double-sided carbon tape on an aluminum stub was coated with gold and then SEM images were recorded on a JEOL microscope, model JSM 6610LV, operating with a Secondary Electron Imaging (SEI) detector.

\section{Moisturizing cosmetic formulation containing SBA-15Urea}

For the base gel $3.0 \mathrm{~g}$ of hydroxyethylcellulose (HEC), $1.6 \mathrm{~g}$ of ProTeg SL preservative (phenoxyethanol + ethyl hexyl glycerin) and $140.3 \mathrm{~g}$ of distilled water were weighed. HEC was added to the water, the mixture being stirred with a glass rod until dissolution. The mixture was then heated to $60{ }^{\circ} \mathrm{C}$, when the gel became clear and viscous. The gel was then cooled to $45^{\circ} \mathrm{C}$ in a water bath and the ProTeg SL preservative was added and the gel homogenized.

After the base gel cooled to room temperature, 75.1 $\mathrm{g}$ of gel were weighed and diluted with distilled water $(25.1 \mathrm{~g})$ to obtain $100.0 \mathrm{~g}$ of base gel.

The cosmetic moisturizer formulation, containing urea $0.1 \%$ by weight, was prepared by mixing the basic gel $(100 \mathrm{~g})$ and SBA-15Urea $(0.5 \mathrm{~g})$. The mixture was homogenized on a Vortex mixer for 15 minutes. The other products were prepared in a similar manner using the same amount of basic gel and $0.5 \mathrm{~g}$ of SBA-15 and $0.5 \mathrm{~g}$ of urea, obtaining $\mathrm{BG}+\mathrm{SBA}-15$ and $\mathrm{BG}+$ Urea, respectively (Figure 2). 


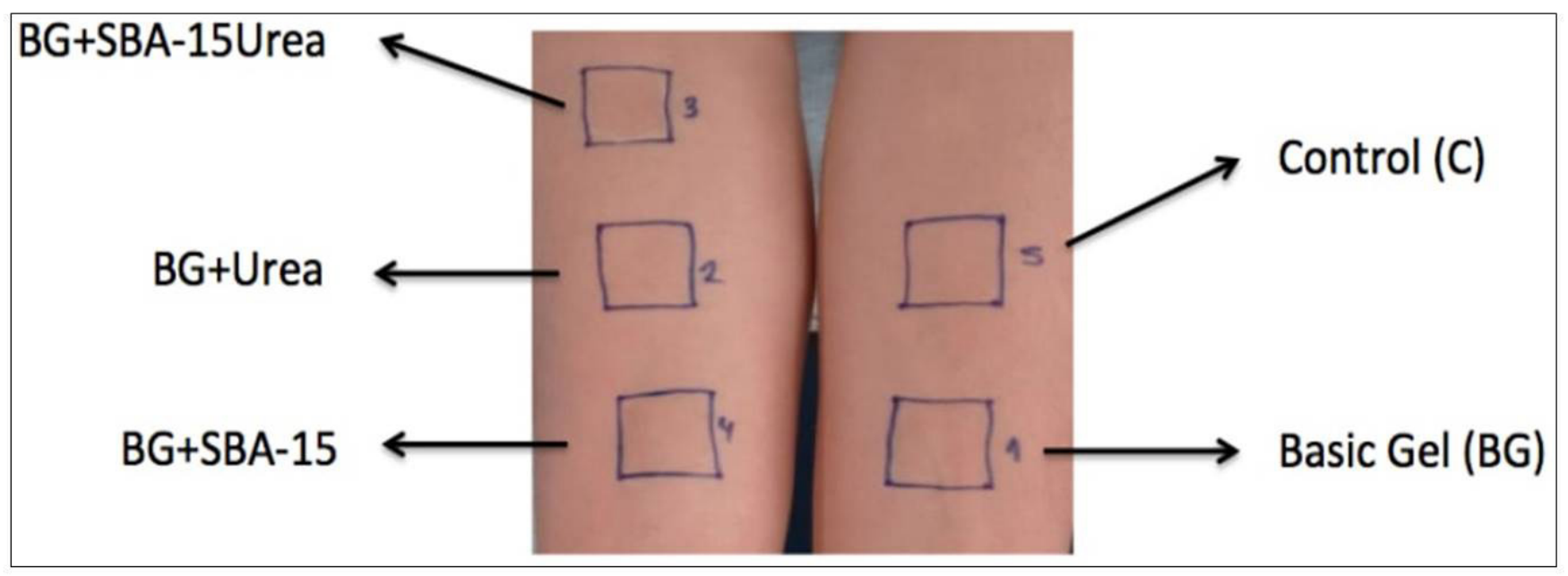

FIGURE 2 - Scheme of samples application onto forearm. Samples had just been applied onto the squares.

\section{In vivo moisturize studies}

This was a blind and randomized study to measure skin hydration and transepidermal water loss (Chaves at al., 2014). A sensorial test was carried out under controlled conditions $\left(25 \pm 2{ }^{\circ} \mathrm{C}\right.$ and $55 \pm 5 \%$ relative humidity) where volunteers were instructed not to leave the testing site, not expose themselves to the sun, not consume caffeine, not use 24-hour moisturizing creams prior to testing. The 6 volunteers were between 18 and 40 years old. Study was approved by the Ethics Committee of the Federal University of São Paulo Number 1.113.126.

To measure the amount of water in the stratum corneum and transepidermal water loss (TEWL), Corneometer ${ }^{\circledR}$ CM 825 PC Courage-Khazaka (Cologne, Germany) and Tewameter ${ }^{\circledR} 300$ TM Courage-Khazaka (Cologne, Germany) were used (Courage-Khazaka Eletronic GMBH, 2009a; Courage-Khazaka Eletronic GMBH, 2009b).

Five different formulations were applied at $2.0 \mathrm{mg}$ $\mathrm{cm}^{-2}$ in different areas of the forearm and named by 1 , 2, 3, 4 and 5 .

The measurements were performed immediately before application and after 1, 2, 3, 4 and $5 \mathrm{~h}$ (Chaves et al., 2014; Choi et al., 2013; Leite-Silva, et al., 2009). Hydration and transepidermal water loss data were analyzed by one way ANOVA with Tukey test, using Statistica 13.0 (TIBCO Software Inc., CA, USA) software to evaluate differences or any relationship between formulations and the obtained results.

\section{RESULTS AND DISCUSSION}

\section{SAXS analysis}

Structural properties of ordered mesoporous silica with and without urea were evaluated by SAXS. Figure 3 illustrates the curves SAXS of SBA-15 and SBA15 Urea.

As evident in Figure 3, both diffractograms contain five intense diffraction peaks, indexable as (100), (110) (200), (210) and (300) reflections, which are characteristics of SBA-15 that has a highly ordered 2D hexagonal mesostructure, space group p6mm (Zhao et al., 1998b; Jardim at al., 2016). However, it was observed that the intensity of the diffraction peaks of SBA15Urea decreased compared to pure SBA-15, indicating inclusion of urea in the SBA-15 pores. Table I shown the interplanar spacing $\left(\mathrm{d}_{(\mathrm{hkl})}\right)$ and lattice parameter $\left(\mathrm{a}_{(\mathrm{hkl})}\right)$ values. The lattice parameter values (Table I) of SBA-15Urea slightly decreased but this was expected due to the heating of silica for water removal before the incorporation process. 


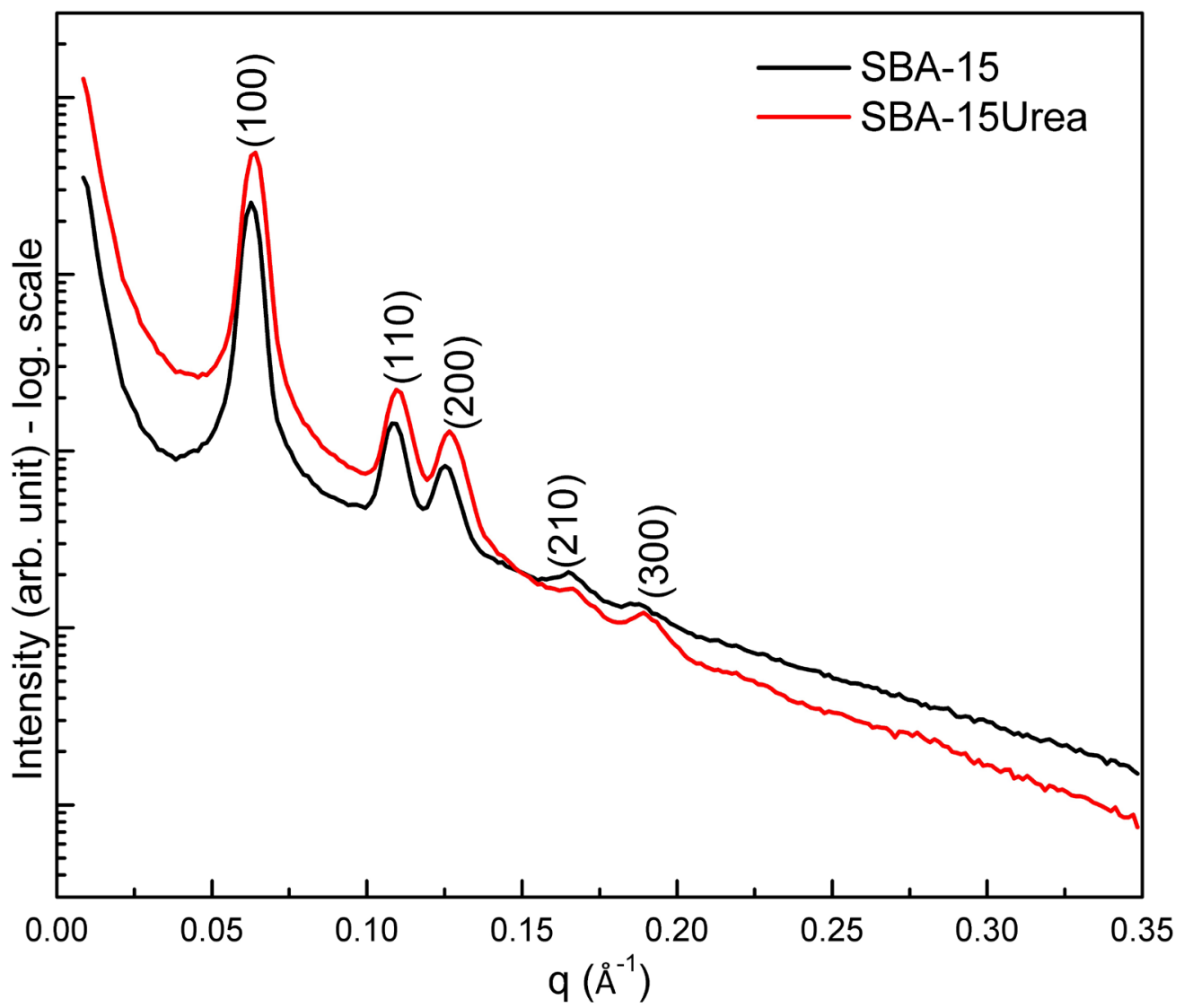

FIGURE 3 - SAXS Curves of SBA-15 and SBA-15Urea.

TABLE I - Structural properties determined from SAXS curves of SBA-15 and SBA-15Urea samples

\begin{tabular}{|c|c|c|c|c|c|c|c|c|c|c|}
\hline \multirow{2}{*}{ Samples } & \multicolumn{5}{|c|}{$d_{(h k l)}(n m)$} & \multicolumn{5}{|c|}{$\mathbf{a}_{(\mathrm{hkl})}(\mathrm{nm})$} \\
\hline & (100) & (110) & (200) & (210) & (300) & (100) & (110) & $(200)$ & (210) & (300) \\
\hline SBA-15 & 10.13 & 5.82 & 5.03 & 3.81 & 3.32 & 11.69 & 11.64 & 11.62 & 11.64 & 11.50 \\
\hline SBA-15Urea & 9.82 & 5.71 & 4.95 & 3.81 & 3.31 & 11.34 & 11.42 & 11.43 & 11.64 & 11.47 \\
\hline
\end{tabular}

$a_{(h k l),}$ lattice parameter; $d_{(h k l)}$, interplanar spacing. The error of the lattice parameter is $2 \%$.

\section{SEM analysis}

The morphology of the SBA-15 sample analyzed by SEM (Figure 4) was similar to that observed by Zhao et al. (Zhao at al., 1998b). The SBA-15 powder shows many rope-like domains with uniform particle size of about $1 \mu \mathrm{m}$, while retaining the well-defined wheat-like macrostructure clusters of SBA-15. 


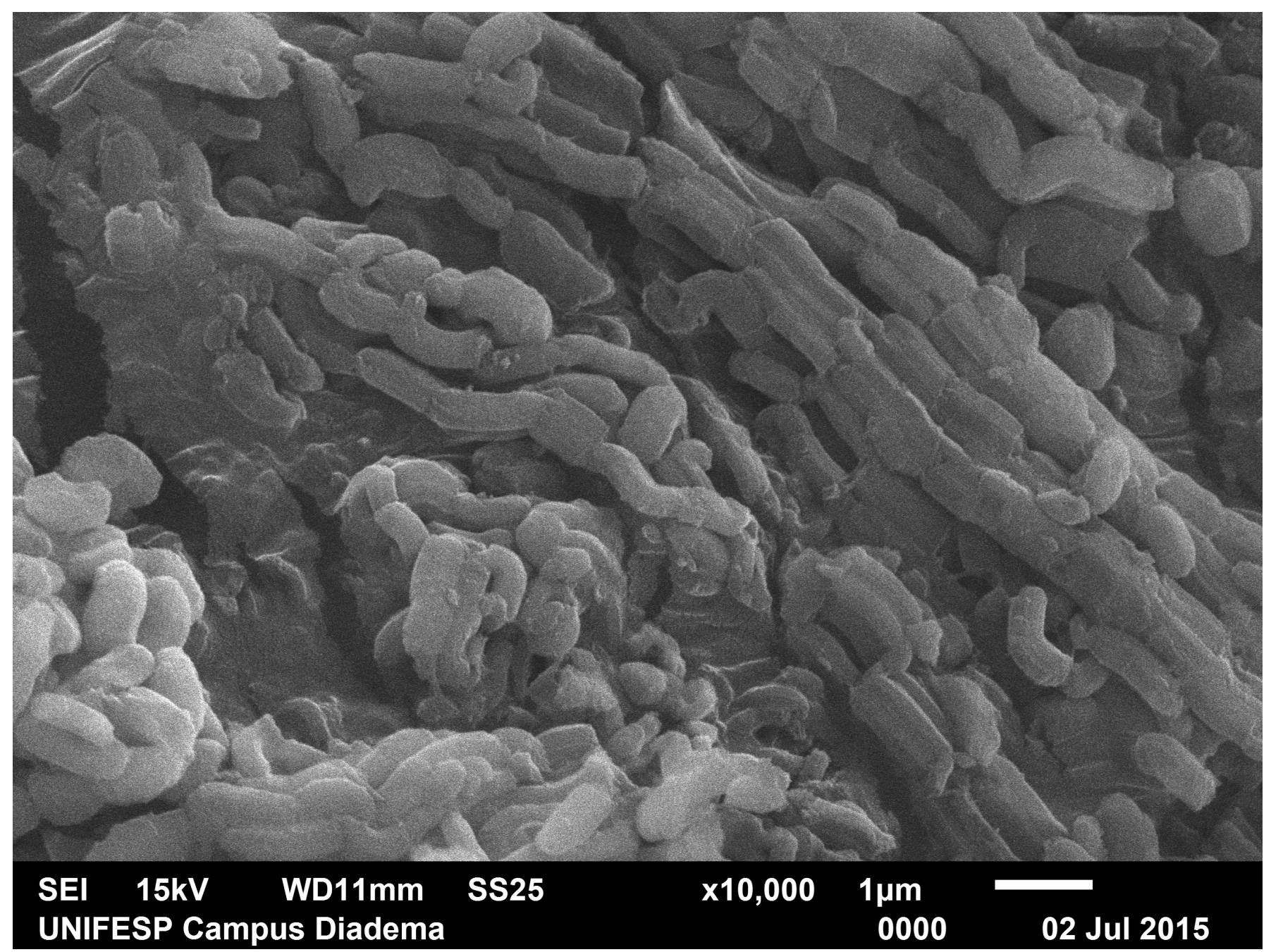

FIGURE 4 - SEM micrograph of SBA-15.

\section{Nitrogen physisorption analysis}

Nitrogen adsorption-desorption isotherms and pore size distribution are shown in Figure 5 and Figure 6 , respectively. The textural properties obtained by $\mathrm{N}_{2}$ sorption of SBA-15 and SBA-15Urea are summarized in Table II. For both samples, the isotherms exhibited type-IV behavior and H1 hysteresis loops (Sing at al.,
1985) typical of SBA-15 indicating that even after urea incorporation the hexagonal pore structure of SBA15 was preserved, corroborating the SAXS results. The surface area and pore volume (Table II) of SBA15Urea decreased compared to SBA-15, probably due to presence of urea into the mesoporous of SBA- 15 . The pore size distribution (Figure 6 ) of both samples is similar. 


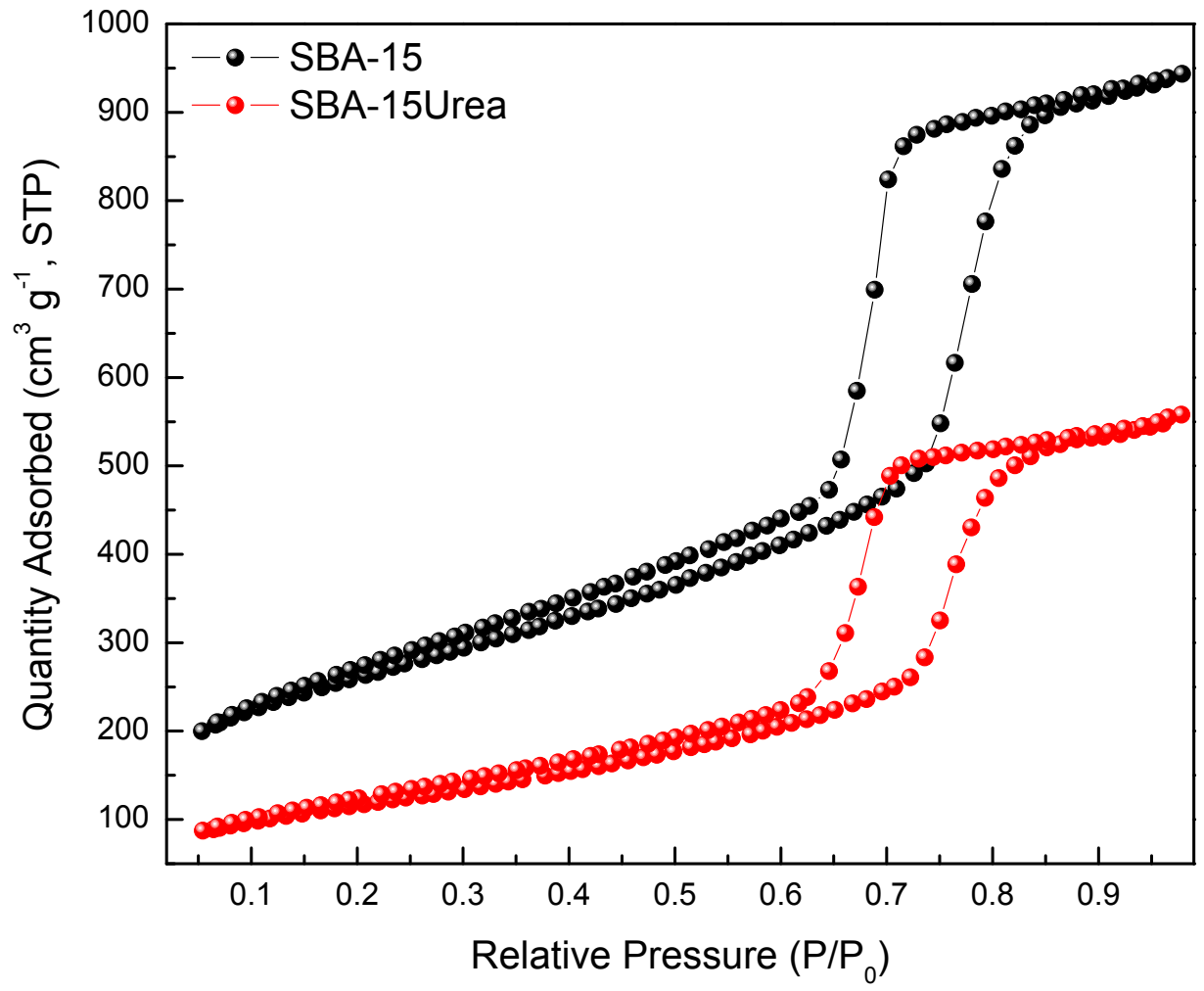

FIGURE 5 - Adsorption-desorption isotherms in $\mathrm{N}_{2}$ at $77 \mathrm{~K}$ of SBA-15 and SBA-15Urea.

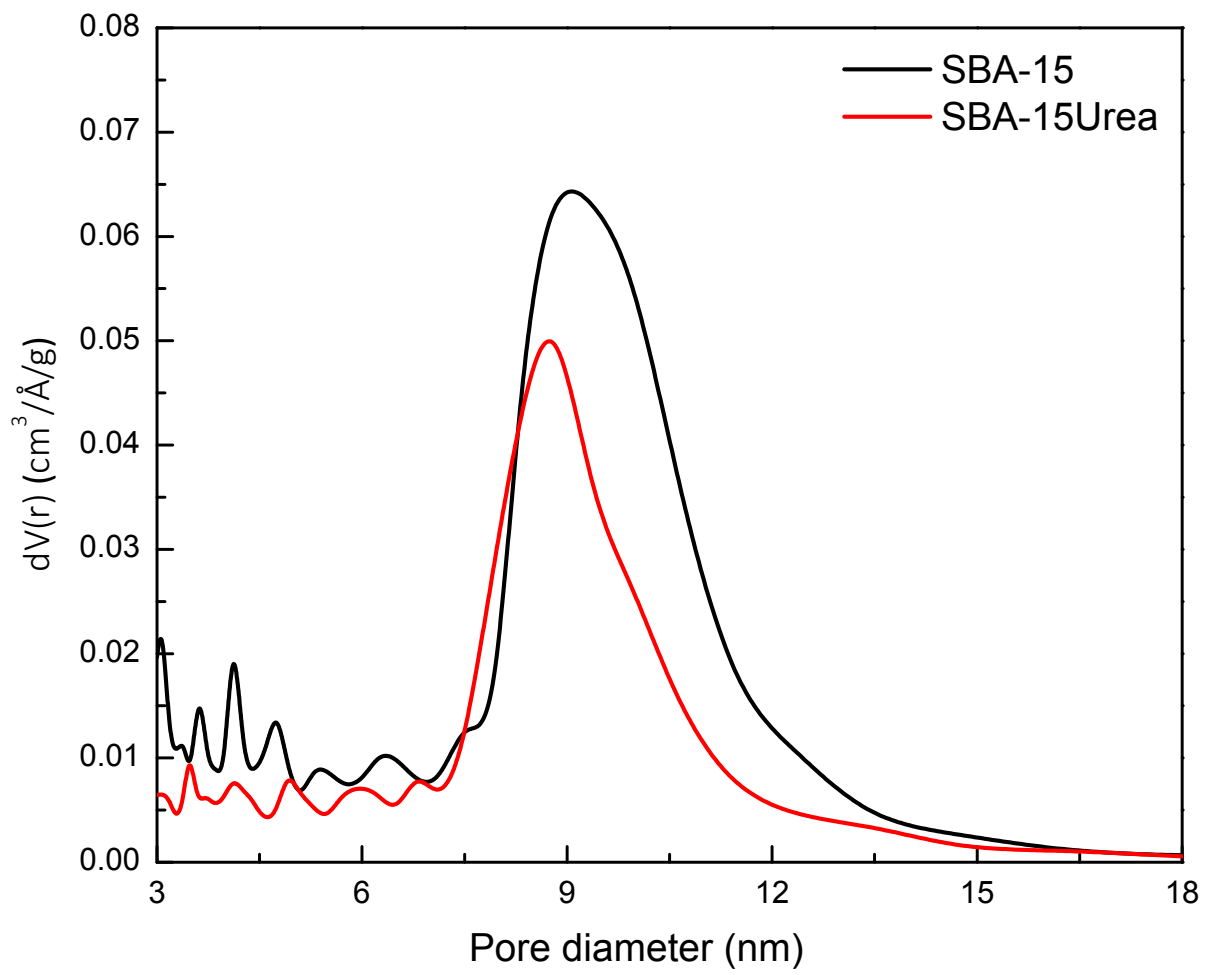

FIGURE 6 - Pore size distribution of SBA-15 and SBA-15Urea. 
TABLE II - Textural properties of SBA-15 and SBA-15Urea samples obtained by $\mathrm{N}_{2}$ sorption

\begin{tabular}{lccc}
\hline Samples & $\mathbf{S}_{\mathbf{B E T}}\left(\mathbf{m}^{2} \cdot \mathbf{g}^{-1}\right)$ & $\mathbf{V}_{\mathbf{P}}\left(\mathbf{c m}^{3} \cdot \AA . \AA . \mathbf{g}^{-1}\right)$ & $\mathbf{D}_{(\mathbf{B J H})}(\mathbf{n m})$ \\
\hline SBA-15 & 947.15 & 1.28 & 8.8 \\
SBA-15Urea & 420.70 & 0.84 & 8.8 \\
\hline
\end{tabular}

$S_{(B E T)}$, BET specific surface area; $D_{B J H}$ average pore diameter; $V_{p}$, mesopore volume.

\section{FTIR spectroscopy}

The FTIR spectra of the samples are shown in Figure 7. In SBA-15 and SBA-15Urea samples, a broad absorption band characteristic of silanol groups (vSiO-H) was observed at 3100 and $3700 \mathrm{~cm}^{-1}$, which was attributed to $\mathrm{OH}$ stretching of silanol groups and adsorbed water. In the region around $1080-1210 \mathrm{~cm}^{-1}$ an intense broad band was attributed to $\mathrm{Si}-\mathrm{O}-\mathrm{Si}$ asymmetric stretching $\left(\mathrm{v}_{\text {as }}(\mathrm{Si}-\mathrm{O}-\mathrm{Si})\right)$. The band at $960 \mathrm{~cm}^{-1}$ was attributed to the stretching vibration of the $\mathrm{vSi}-\mathrm{OH}$. The characteristic bands of the siloxanes groups noted around 800 and $470 \mathrm{~cm}^{-1}$ were attributed to $\mathrm{Si}-\mathrm{O}-\mathrm{Si}$ symmetric stretching $\left(\mathrm{v}_{\mathrm{s}}(\mathrm{Si}-\mathrm{O}-\mathrm{Si})\right)$ and $\delta(\mathrm{O}-\mathrm{Si}-\mathrm{O})$, respectively. The band at $1632 \mathrm{~cm}^{-1}$ was assigned to a water bending vibration (Jardim at al., 2016; Prado et al., 2005).

In the FTIR spectrum of the SBA-15Urea sample (Figure 7), the main characteristic infrared bands of urea $\left(\mathrm{v}\left(\mathrm{NH}_{2}\right)\right.$ vibration at $3500-3000 \mathrm{~cm}^{-1}, \mathrm{v}(\mathrm{CO})$ and $\delta\left(\mathrm{NH}_{2}\right)$ vibrations around 1680-1620 $\mathrm{cm}^{-1}$ and $\mathrm{v}_{\mathrm{s}}\left(\mathrm{NH}_{2}\right)$ and $\mathrm{V}_{\text {as }}\left(\mathrm{NH}_{2}\right)$ vibrations at 1150 and $1058 \mathrm{~cm}^{-1}$, respectively) were overlapped with the $\mathrm{OH}$ stretching of silanol groups and adsorbed water, water bending vibration and siloxanes groups. Only the $v_{\text {as }}(\mathrm{CN})$ vibration band, at $1460 \mathrm{~cm}^{-1}$ appeared to be resolved. Therefore we have not observed significant band shifts to indicate that silica interacts slightly with the urea (Keuleers at al. 1999).

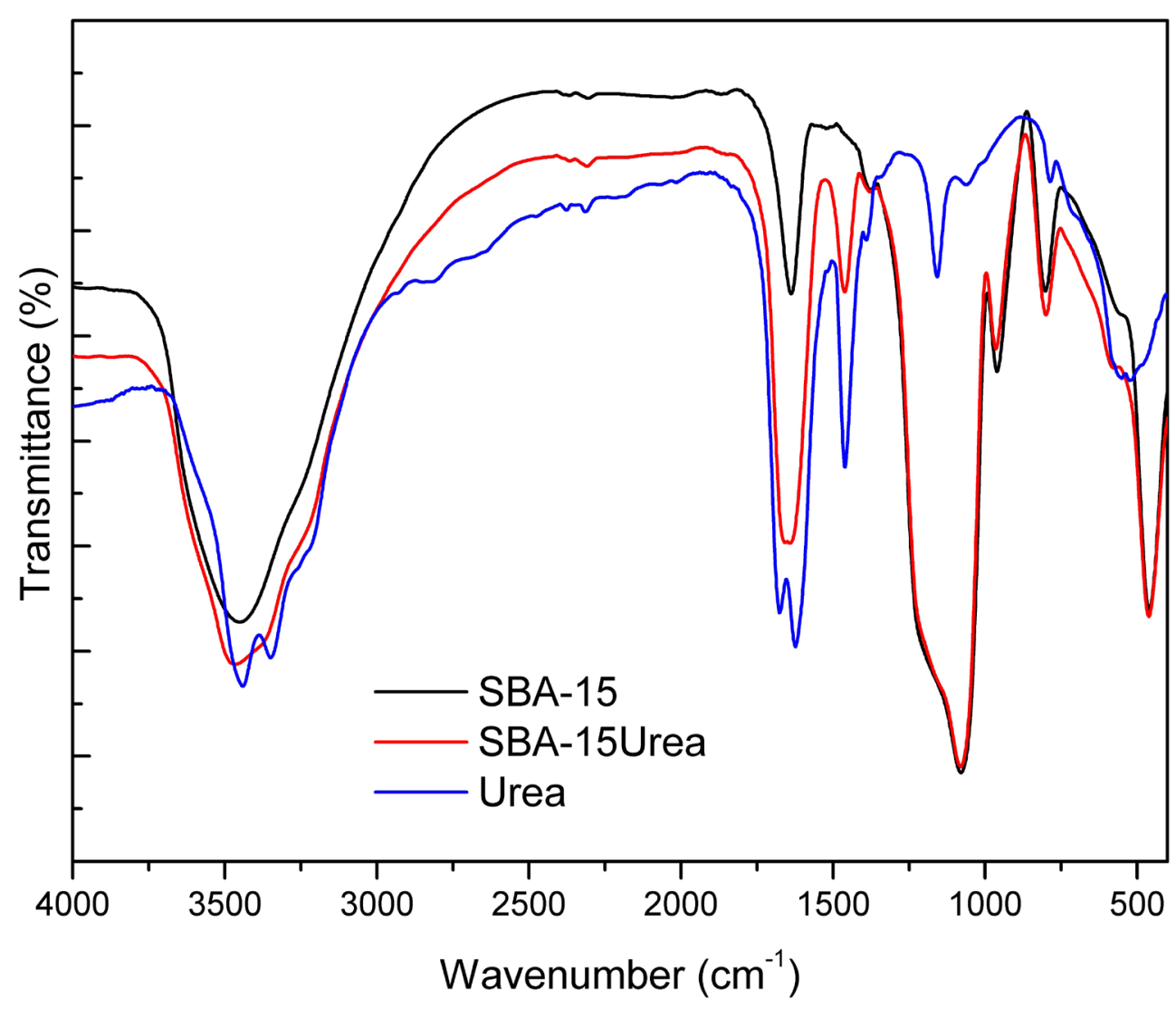

FIGURE 7 - FTIR spectra of SBA-15, SBA-15Urea and urea. 


\section{TG/DTA analysis}

The TG/DTA curves for all samples are shown in Figure 8 and Figure 9. The TG curve of urea (Figure 8) show three events of weight loss that corresponds to thermal decomposition of urea $\left(\left(\mathrm{NH}_{2}\right)_{2} \mathrm{CO}(\mathrm{s}) \rightarrow\right.$ $\left.\mathrm{NH}_{3}(\mathrm{~g})+\mathrm{HNCO}(\mathrm{g})\right)$ in the temperature range of 150 $430{ }^{\circ} \mathrm{C}$, which are accompanied by three endothermic peaks in the DTA curve. At $450{ }^{\circ} \mathrm{C}$ the decomposition products of urea were completely eliminated and no residue remained. An endothermic peak, at $141{ }^{\circ} \mathrm{C}$, corresponds to the melting point of urea (Khattab at al., 1984). The TG curve of calcined SBA-15 (Figure 9) indicates that Pluronic ${ }^{\circledR}$ P123 was completely removed. The two events of weight loss (from 25 to $700{ }^{\circ} \mathrm{C}$ ) could be attributed to elimination of water (from 25 to
$90{ }^{\circ} \mathrm{C}, 7 \%$ weight loss) and dehydroxylation of surface silanols (from 90 to $700{ }^{\circ} \mathrm{C}, 6 \%$ weight loss). The TG curve of SBA-15Urea (Figure 9) shows two events of weight loss, in the temperature range from 25 to 700 ${ }^{\circ} \mathrm{C}$. The first event $\left(25-130{ }^{\circ} \mathrm{C}\right)$, with $8 \%$ weight loss, corresponds to the loss of physically adsorbed water and the second event $\left(130-700{ }^{\circ} \mathrm{C}\right)$, with $21 \%$ weight loss, was designated to the urea loss and some residual silanol. The percentage of mass loss obtained by TG is similar the nominal amount of urea used. Comparing the TG curves of urea and SBA-15Urea, it was noted that the onset temperature for urea decomposition was higher $\left(173{ }^{\circ} \mathrm{C}\right)$ for pure urea than for SBA-15Urea $\left(151{ }^{\circ} \mathrm{C}\right)$. However, the final temperature of thermal decomposition was greater for SBA-15Urea than for pure urea.

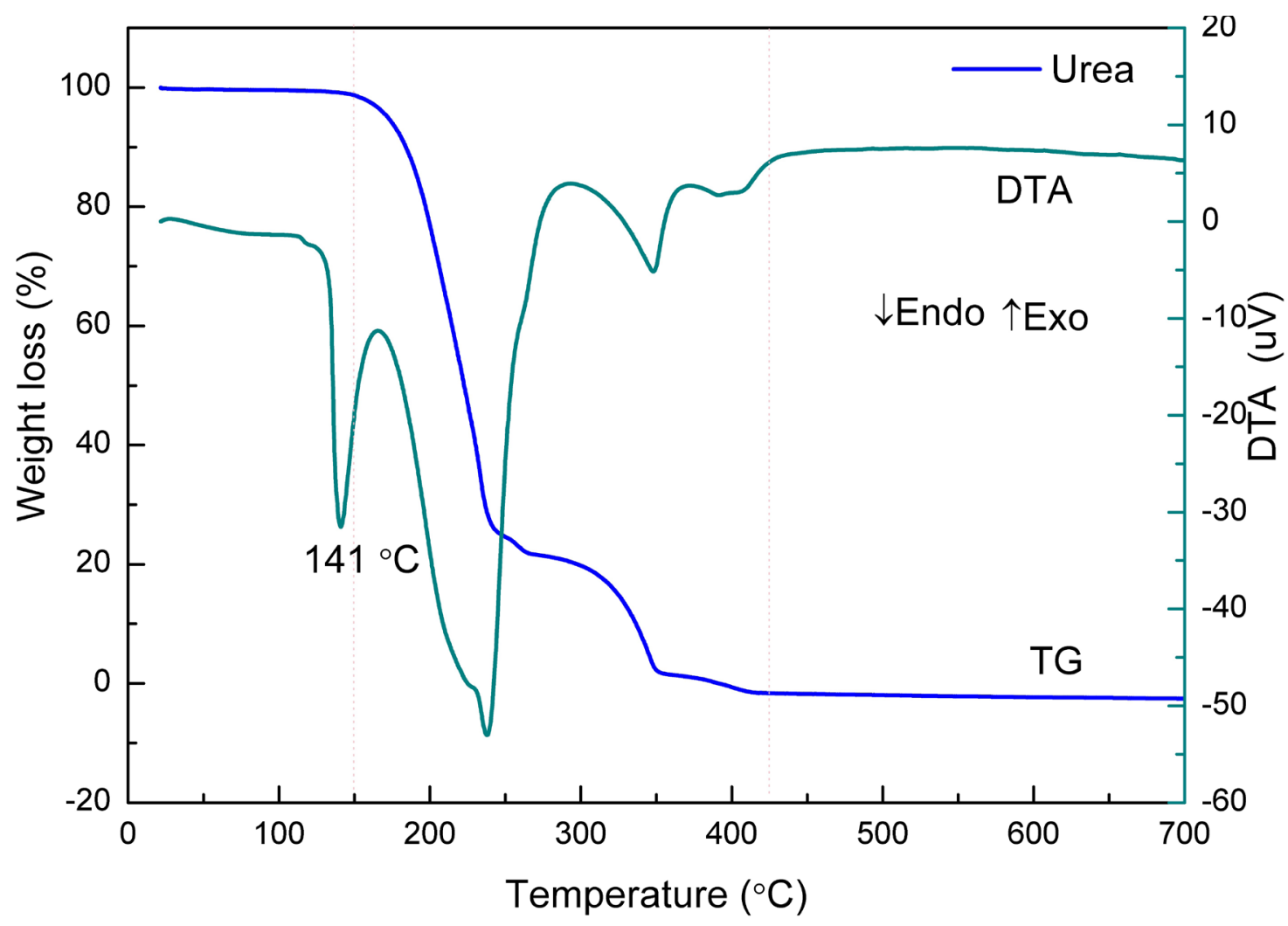

FIGURE 8 - TG-DTA curves of the pure urea sample. 


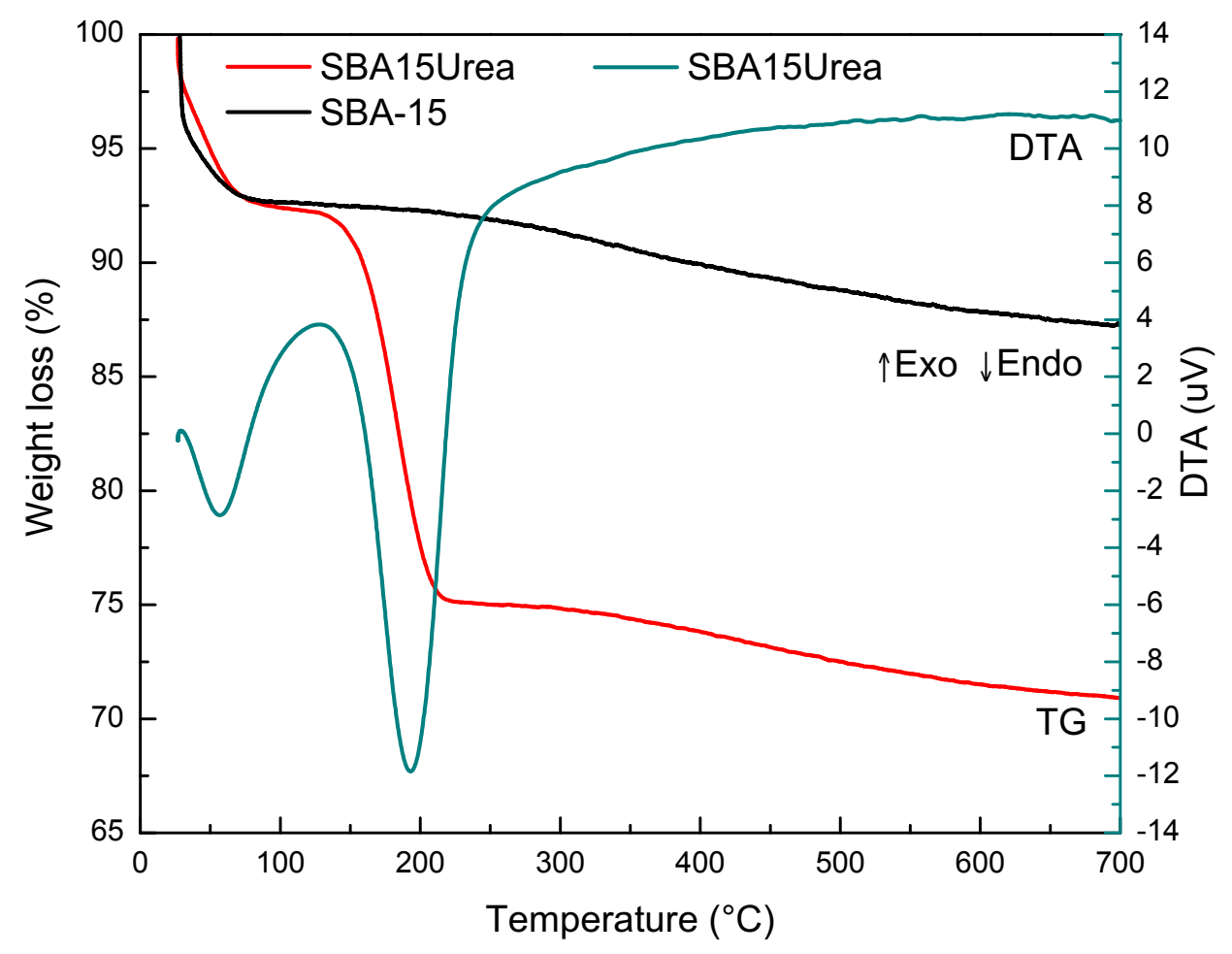

FIGURE 9 - TG-DTA curves of the SBA-15Urea sample and TG curve of the calcined SBA-15.

\section{In vivo moisturization studies}

A degree of whitening was observed in the in vivo moisturization studies after the natural drying of samples 3 (BG+SBA-15Urea) and 4 (BG+SBA-15) as shown in Figure 10. This phenomenon is due to the presence of SBA-15 in which individual particles (approximately $1 \mu \mathrm{m}$ ) are aggregate into blocks. Whitening was not observed for sample 2 (BG+Urea) which lacked SBA-15.

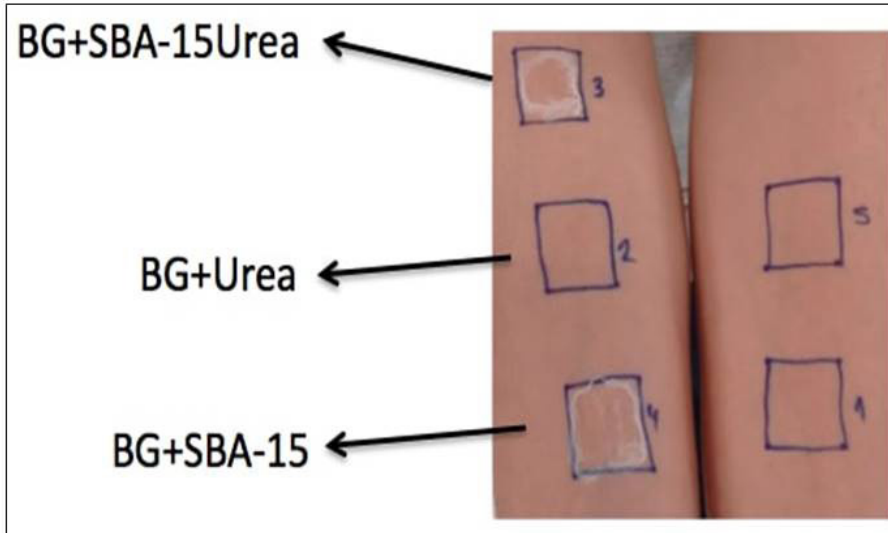

(A)

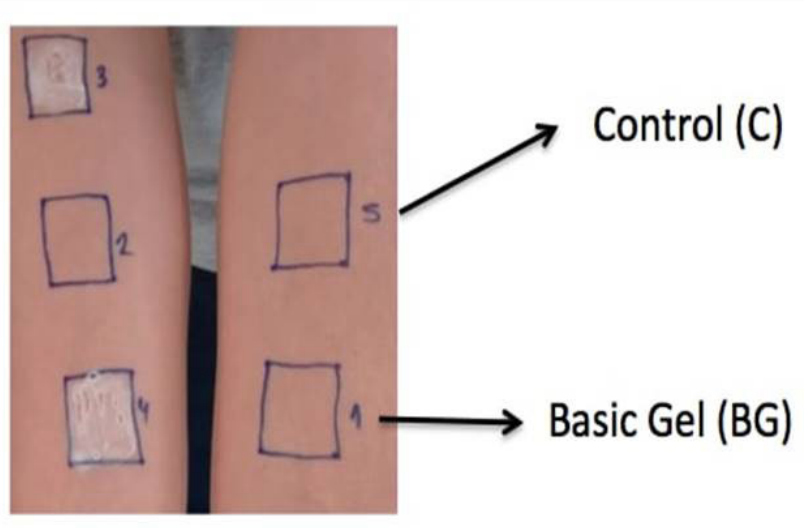

(B)

FIGURE 10 - Appearance of samples after (A) 40 min after application and (B) after two hours of application. 
Figure 11 shows skin hydration measured at 0, 1, 2, 3, 4 and 5 hours (T0, T1, T2, T3, T4 and T5, respectively) after application of basic gel (BG), basic gel with urea (BG+Urea), basic gel with urea in ordered mesoporous silica SBA-15 (BG+SBA-15Urea) and basic gel with ordered mesoporous silica SBA-15 without urea (BG+SBA-15), as well as an untreated control area $(\mathrm{C})$.

The variation of hydration values between $\mathrm{T} 0$ to T5 was not significant for BG $(\mathrm{p}=0.3025)$ by one-way ANOVA or $\mathrm{C}(\mathrm{p}=0.1141)$. These results were expected, as $\mathrm{BG}$ is the basic gel vehicle without a moisturizing agent (urea) and $\mathrm{C}$ is the untreated control.

However, a significant difference versus time was observed for BG+Urea $(\mathrm{p}=0.0297), \mathrm{BG}+\mathrm{SBA}-15 \mathrm{Urea}$ $\left(\mathrm{p}=8.14 \times 10^{-5}\right)$ and $\mathrm{BG}+\mathrm{SBA}-15\left(\mathrm{p}=3.91 \times 10^{-7}\right)$. Tukey test showed that hydration values of $\mathrm{T} 0$ (30.26) and $\mathrm{T} 1$ (41.34) for BG+Urea were significantly different from each other and from T2 (38.47), T3 (36.61), T4 (38.19) and T5 (36.99). T0 corresponds to the measurement of skin hydration immediately before applying the product. For $\mathrm{BG}+$ Urea, urea incorporated into the basic gel showed a higher hydration by the first hour that remained constant for the subsequent measurement period, T1-T5 $(\mathrm{p}=0.5140)$.

Tukey test showed that T0 was significantly different from T1, T2, T3, T4 and T5 for BG+SBA15Urea and for BG+SBA-15. It is observed in Figure 12 that there is a reduction in hydration values from $\mathrm{T} 0$ to T1, T2, T3, T4 and T5 for both products. However, there was an increase in the degree of whitening over the experiment time period.

Since there was no difference between hydration values from $\mathrm{T} 1$ to $\mathrm{T} 5$ for $\mathrm{BG}(\mathrm{p}=0.2334), \mathrm{BG}+$ Urea ( $p$ $=0.5140), B G+$ SBA-15Urea $(p=0.9555), B G+$ SBA-15 $(p=0.7857)$ and $C(p=0.1688)$, the average values were calculated as shown in Figure 12.

Comparing the average hydration values (Figure 12) from $T 1$ to $T 5$ using one-way ANOVA, $p$-value was $2.29 \times 10^{-17}$ indicating a high significantly difference between the products, considering $\mathrm{p}<0.05$. By means of Tukey test, it was possible to separate the products into groups (Table III).

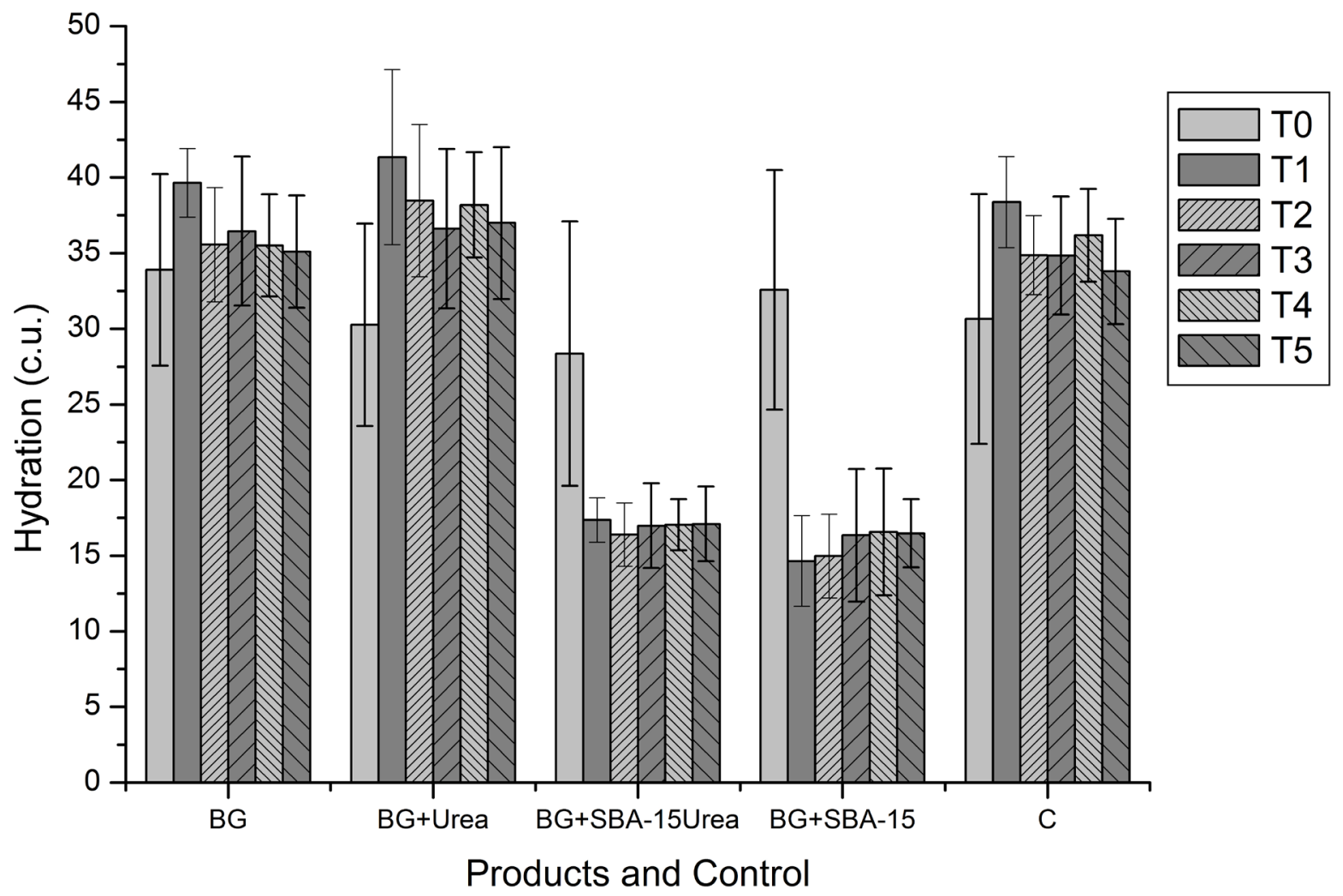

FIGURE 11 - Hydration measured as capacitance of a dielectric medium in Corneometer ${ }^{\circledR}$ units (c.u.) versus products (BG, BG+Urea, BG+SBA-15+Urea, BG+SBA-15 and C). Error bars are the standard deviation. 


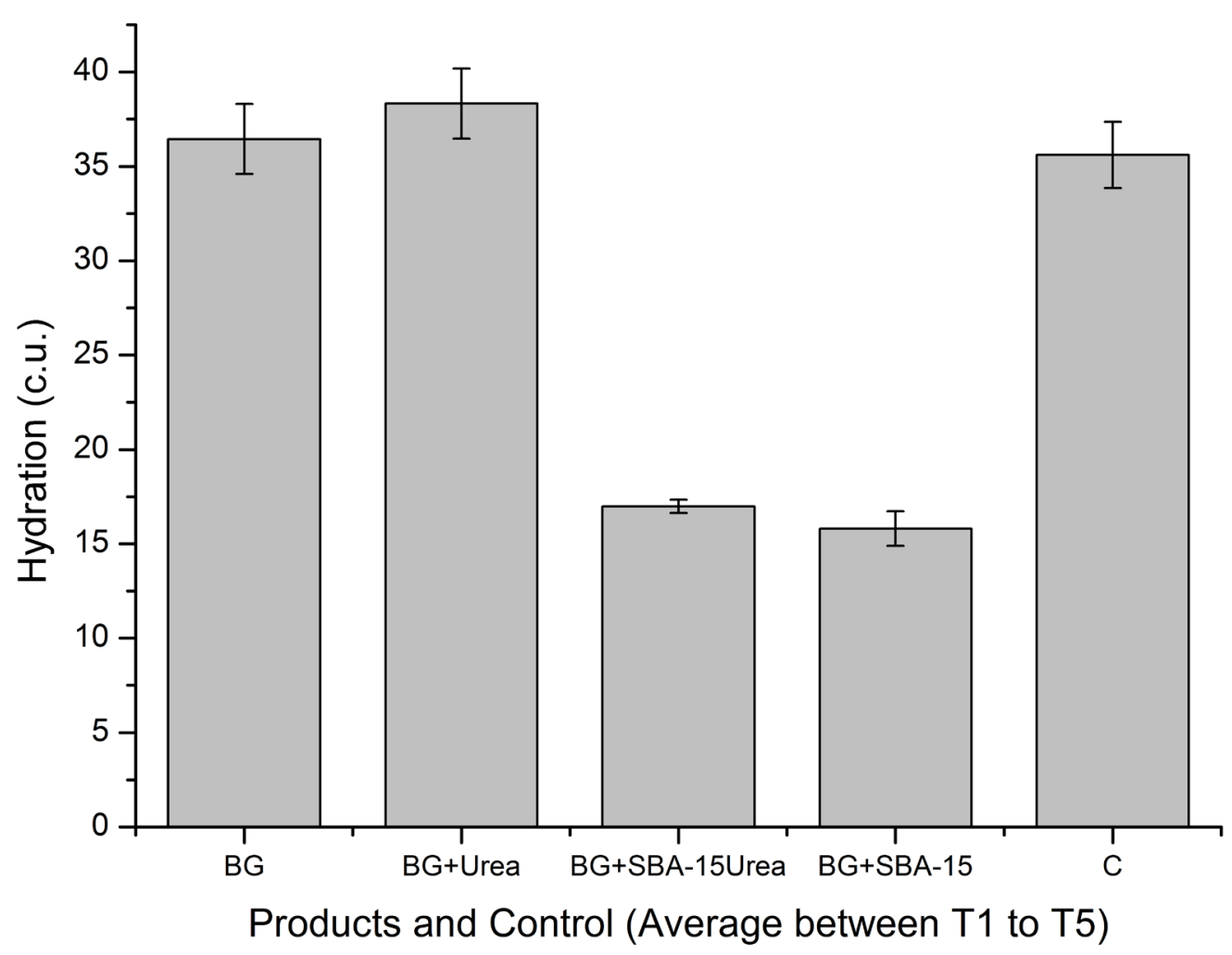

FIGURE 12 - Average hydration values $(\mathrm{n}=5)$ from $\mathrm{T} 1$ to $\mathrm{T} 5$ for each product (BG, BG+Urea, BG+SBA-15Urea, BG+SBA-15) and Control $(\mathrm{C})$. Error bars are the standard deviation $(\mathrm{p}<0.05)$.

TABLE III - Clusters of the products according to the Tukey test into two groups (1 and 2 ) for Corneometer values

\begin{tabular}{lccc}
\hline Product & Corneometer & $\mathbf{1}$ & $\mathbf{2}$ \\
\hline BG+Urea & 38.32 & $* * * *$ & \\
BG & 36.45 & $* * * *$ & \\
C & 35.60 & $* * * *$ & \\
$\begin{array}{l}\text { BG+SBA- } \\
\text { 15Urea }\end{array}$ & 16.97 & & $* * * *$ \\
BG+SBA-15 & 15.79 & & $* * * *$ \\
\hline
\end{tabular}

The hydration state of the skin surface is commonly evaluated by an indirect method based on the measurement of electrical conductivity of percentage of water present in the horny layer (Tagami, 1995). This is the method used by the Corneometer ${ }^{\circledR}$. The presence of whitening areas at the forearm squares with samples containing SBA-15 indicates film formation, which might have masked the correct reading of the degree of hydration of the Corneometer ${ }^{\circledR}$. A standardized wash procedure should be performed on the skin to obtain a correct reading with the Corneometer ${ }^{\circledR}$. In addition, the skin surface hydration should be measured within the next day as recommended by Imokawa for nontransparent cosmetic (Imokawa, 1989). Although most studies required an overnight washout period prior to measurement, this could have had an influence on the results (Lodén, 2012).

Transepidermal water loss (TEWL) for products $\mathrm{BG}, \mathrm{BG}+\mathrm{Urea}, \mathrm{BG}+\mathrm{SBA}-15 \mathrm{Urea}, \mathrm{BG}+\mathrm{SBA}-15$ and control (C) are shown in Figure 13. 


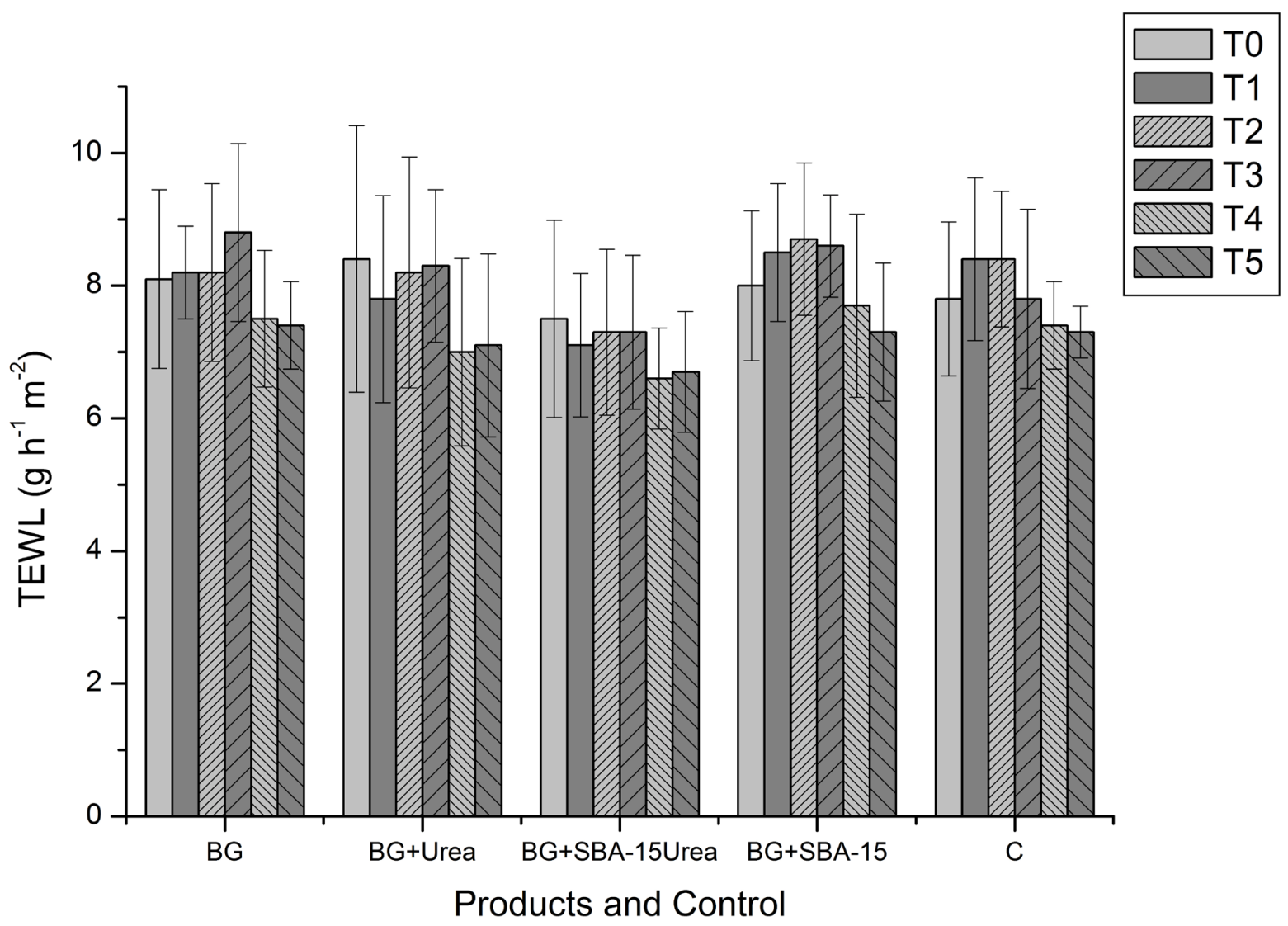

FIGURE 13 - Transepidermal water loss obtained using Tewameter $^{\circledR}$ versus products (BG, BG+Urea, BG+SBA-15Urea, BG+SBA-15 and C). Error bars are the standard deviation.

TEWL values of each product per time (T0, T1, T2, T3, T4 and T5) were compared using one-way ANOVA. No found significant differences were seen for TEWL when comparing the values obtained for each time point for BG $(\mathrm{p}=0.2733), \mathrm{BG}+$ Urea $(\mathrm{p}=0.4540), \mathrm{BG}+\mathrm{SBA}-$ 15Urea $(\mathrm{p}=0.7243), B G+\operatorname{SBA}-15(\mathrm{p}=0.2060)$ or $\mathrm{C}(\mathrm{p}$ $=0.3314)$.

Since the variation found for transepidermal water loss was not statistically significant during five hours of measurement for each product and control, the average TEWL between T0 to T5 were calculated (Figure 14).

Average TEWL of each product (Figure 14) was compared using one-way ANOVA. The results showed significant differences $(p=0.014)$ between the products. Tukey test showed clusters of the products into three groups: $1(\mathrm{BG}+\mathrm{SBA}-15$ and $\mathrm{BG}), 2(\mathrm{BG}+\mathrm{Urea}$ and $\mathrm{C})$ and 3 (BG+SBA-15Urea). BG+SBA-15Urea was effective in reducing transepidermal water loss compared to the other products and control.

A review on the clinical effectiveness of moisturizers suggested that urea-based preparations may be preferable as a first-line treatment, but there was an unmet need for well-powered comparisons between individual moisturizers (Lindh, 2015).

Many papers have shown that urea increase skin moisturization but does not reduce TEWL corroborating this study. In two small-randomized controlled trials, urea-containing moisturizers were not significantly superior to any other treatment in reducing TEWL [Lodén, at al., 1999; Hagströmer, at al. 2001). 


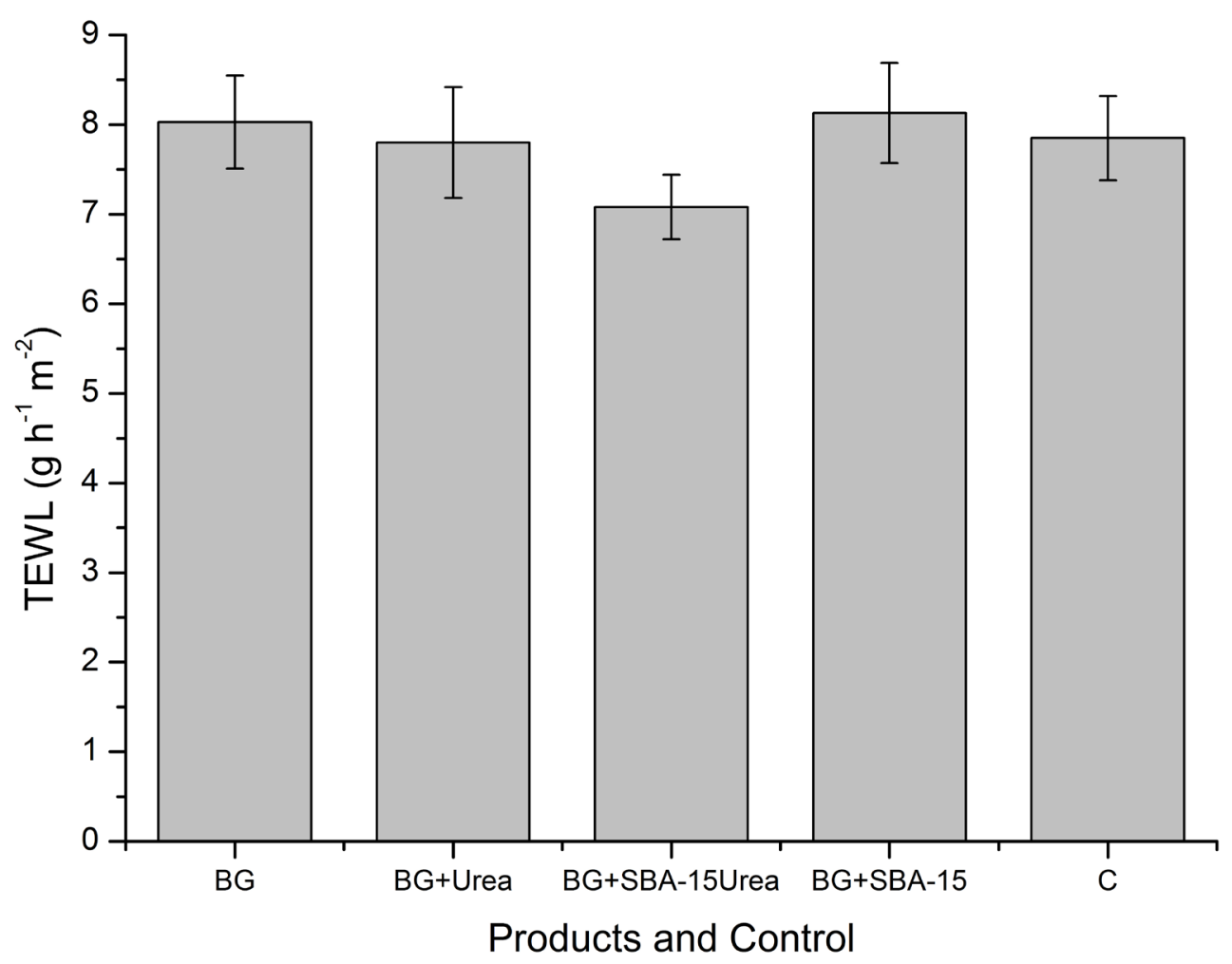

FIGURE 14 - Average transepidermal water loss values $(\mathrm{n}=6)$ from $\mathrm{T} 0$ to $\mathrm{T} 5$ for each product (BG, BG+Urea, BG+SBA-15Urea, $\mathrm{BG}+\mathrm{SBA}-15)$ and Control (C). Error bars are the standard deviation.

\section{CONCLUSIONS}

The synthesis of the SBA-15 matrix was reproducible and the estimated values of surface area, pore size and pore volume were similar to those reported in the literature. Urea was incorporated into SBA-15 at approximately $21 \mathrm{wt} . \%$, and results indicated that it was deposited inside the mesopores and caused little change to the structural integrity of SBA-15.

The presence of whitened regions on the forearm where SBA-15 and SBA-15Urea were applied suggests that these materials formed a film on the skin surface, probably due to the nanotubes being aggregated. This film was not occlusive, however, no change in transepidermal water loss was observed on treated areas over five hours after application. On the other hand, skin hydration readings at these times for the SBA-15 and SBA-15Urea treated skin were only $50 \%$ of basal or control values and we believe that the film prevented good contact of the corneometer probe with the skin surface, resulting in measurements that were not truly indicative of the underlying skin properties. This scenario is likely, as the skin below the film is expected to be well hydrated in the presence of urea.

With their five hours retention on the skin surface, the SBA15 materials used in this work are promising vehicles for providing long-lasting moisturizing, in combination with urea or other raw materials. Future studies by this group will investigate new methods of decreasing aggregation of the nanotubes, to promote better dispersion of SBA15 in the formulation.

\section{ACKNOWLEDGMENTS}

The authors would thank Ms. A.C.F. Silveira and Prof. M.C.A. Fantini from Instituto de Física (USP) for SAXS analyses, C.M. Fukumoto, R.M. da Silva, R. Rodrigues and S. Pinheiro from CIPE-UNIFESP (Centro de Instrumentação de Pesquisa e EnsinoUNIFESP) for NAI analyses and F. F. Camilo (LMHUNIFESP) and CESQ - POLI - USP for TG/DTA analyses, as well as Fundação de Amparo à Pesquisa do 
Estado de São Paulo (FAPESP) and Conselho Nacional de Desenvolvimento Científico e Tecnológico (CNPq). We owe special thanks to Dr Jeff Grice (a native English speaker) from University of Queensland, Australia, for his careful and excellent English language revision of our manuscript.

\section{REFERENCES}

Agência Nacional de Vigilância Sanitária (Anvisa). BRASIL. Utilização da ureia em produtos cosméticos. Parecer técnico, n. 5, 21 dez. 2010. Disponível em: <http://portal.anvisa.gov. $\mathrm{br} / \mathrm{wps} / \mathrm{wcm} /$ connect/663d73804745936a9b4ddf3fbc4c6735/ $\mathrm{P}$ a r e c e r $+\mathrm{n}+5+-+\mathrm{Ur}$ e i a $++21+12+2010$. pdf?MOD=AJPERES $>$. Acesso em: 07 jun. 2015.

Alothman ZA. A review: fundamental aspects of silicate mesoporous materials. Materials. 2012;5(12):2874-902.

Ayad MM, Salahuddin NA, El-Nasr AA, Torad NL. Aminefunctionalized mesoporous silica KIT-6 as a controlled release drug delivery carrier. Microporous Mesoporous Mater. 2016;229:166-177.

Barrett EP, Joyner LG, Halenda PP. The determination of pore volume and area distributions in porous substances. I. Computations from nitrogen isotherms. J Am Chem Soc. 1951;73(1):373-380.

Braun K, Pochert A, Lindén M, Davoudi M, Schmidtchen A, Nordström R, et al. Membrane interactions of mesoporous silica nanoparticles as carriers of antimicrobial peptides. J Colloid Interface Sci. 2016;475:161-170.

Brunauer S, Emmet PH, Teller E. Adsorption of gases in multimolecular layers. J Am Chem Soc. 1938;60(2):309-319.

Chaves CAC, D'Agostino MC, Baby AR, Leite-Silva VR. Biometrological methods to in vivo evaluate the skin hydration of different commercial moisturizers containing $10.0 \%$ of urea as the main claim. Biomed Biopharm Res. 2014;11(1):101-110.

Choi JS, Moon WS, Choi JN, Do KH, Moon SH, Cho KK, Han CJ, Choi IS. Effects of seaweed Laminaria japonica extracts on skin moisturizing activity in vivo. J Cosmet Sci. 2013;64(3):193-205.

Courage-Khazaka Eletronic GMBH. Corneometer CM. Disponível em: <http://www.cosmeticsonline. com.br/produtos/arquivos/A27_manual_mpa5_port_ corneometer_18-03-09.pdf $>$. Acesso em: 11 mar. 2015a.
Courage-Khazaka Eletronic GMBH. Sonda Tewameter TM. Disponível em: <http://www.cosmeticsonline. com.br/produtos/arquivos/A38_manual_mpa5_port_ tewameter_18-03-09.pdf >. Acesso em: 11 mar. 2015b.

da Silva LCC, Martins TS, Santos FM, Teotônio EES, Isolani $\mathrm{PC}$, Brito HF, et al. Luminescent europium complexes encapsulated in cage-like cubic ordered mesoporous silica. Microporous Mesoporous Mater. 2006;92(1-3):94-100.

Decaux G, Kengne FG, Couturier B, Vandergheynst F, Musch W, Soupart A. Actual therapeutic indication of an old drug: urea for treatment of severely symptomatic and mild chronic hyponatremia related to SIADH. J Clin Med. 2014;3(3):10431049.

Harivel ACMM, Besse, R. Pure urea cosmetic composition, use, and corresponding implementation method. Patent No WO2011/030077 A2. Laboratoires SVR. Demande Internationale PubliéeenVertu du Traité de Coopérationen Matière de Brevets (PCT); 2011.

Hagströmer L, Nyren M, Emtestam L. Do urea and sodium chloride together increase the efficacy of moisturisers for atopic dermatitis Skin? A comparative, doubleblind and randomized study. Skin Pharmacol Appl Skin Physiol.2001;14(1):27-33.

Imokawa G. Importance of intercellular lipids in waterretention porperties of the stratum corneum: induction and recovery of surfactant dry skin. Arch Dermatol Res. 1989;281(1):45-51.

Jardim AMLF, Bacani R, Camilo FF, Fantini MCA, Martins TS. SBA-15:TiO 2 nanocomposites. I. Synthesis with ionic liquids and properties. Microporous Mesoporous Mater. 2016;228:37-44.

Jiao J, Li X, Zhang S, Liu J, Di D, Zhang Y, et al. Redox and $\mathrm{pH}$ dual-responsive $\mathrm{PEG}$ and chitosan-conjugated hollow mesoporous silica for controlled drug release. Mater Sci Eng. 2016;C67:26-33.

Johansson EM, Corndoba JM, Magnus O. The effects on pore size and particle morphology of heptane additions to the synthesis of mesoporous silica SBA-15. Microporous Mesoporous Mater. 2010;133(1-3):66-74.

Kapuscinska A, Nowak I. The use of urea and its derivatives in the cosmetics industry. Chemik. 2014;68:91-6.

Keuleers R, Desseyn HO, Rousseau B, Van Alsenoy C. Vibrational analysis of urea. J Phys Chem A. 1999;103(24):4621-4630. 
Khattab FI, Al-Ragehy NA, Ahmad AKS. Thermal analysis of urea, fatty acids, and their adducts. Thermochim Acta. 1984;73:47-66.

Leite-Silva VR, Schulman M, Ferelli C, Gimenis JM, Ruas GW, Baby AR, et al. Hydrating effects of moisturizer active compounds incorporated into hydrogels: in vivo assessment and comparison between devices. J Cosmet Dermatol. 2009;8(1):32-39.

Lindh JD, Bradley M. Clinical Effectiveness of Moisturizers in Atopic Dermatitis and Related Disorders: A Systematic Review. Am J Clin Dermatol. 2015;16(5):341-359.

Lodén M, Andersson AC, Lindberg M. Improvement in skin barrier function in patients with atopic dermatitis after treatment with a moisturizing cream (Canoderm). Br J Dermatol. 1999;140(2):264-7.

Lodén M. Effect of moisturizers on epidermal barrier function. Clin Dermatol. 2012;30(3):286-96.

Martins TS, Mahmou A, da Silva LCC, Cosentino IC, Tabacniks MH, Matos JR. Freire RS, Fantini MCA. Synthesis, characterization and catalytic evaluation of cubic ordered mesoporous iron-silicon oxides. Mater Chem Phys. 2010;124(1):713-719.

Mody KT, Popat A, Mahony D, Cavallaro AS, Yu C, Mitter N. Mesoporous silica nanoparticles as antigen carriers and adjuvants for vaccine delivery. Nanoscale. 2013;5(12):5167-79.

Pal N, Bhaumik A. Soft templating strategies for the synthesis of mesoporous materials: Inorganic, organic-inorganic hybrid and purely organic solids. J Colloid Interface Sci. 2013;189:21-41.

Panyachariwat N, Steckel H. Stability of urea in solution and pharmaceutical preparations. J Cosmet Sci. 2014;65(3):187-95

Pérez-Esteve E, Ruiz-Rico M, de la Torre C, Llorca E, Sancenón F, Marcos MD, Amoros P, et al. Stability of different mesoporous silica particles during an in vitro digestion. Microporous Mesoporous Mater. 2016;230:196-207.

Prado A, Faria E, Padilha P. Aplicação e modificação química da sílica gel obtida de areia. Quim Nova. 2005;28(3):544-547.

Sing KSW, Everett DH, Haul RAW, Moscou L, Pierotti RA, Rouquérol J, et al. Reporting physisorpion data for gas/solid systems with special reference to the determination of surface area and porosity. Pure Appl Chem. 1985;57:603-619.
Sore G, Hansenne I. Cosmetic Peeling Method Using Urea. Patent No WO2004/093838 A1. L'Oreal. International Application Published Under The Patent Cooperation Treaty (PCT); 2004.

Tagami H. Measurement of Electrical Conductance and Impedance. In: Serup J, Jemec BE, editor. Handbook of NonInvasive Methods and the Skin. CRC Press; 1995. p. 159-170.

Takamori DY, Bizeto MA, Fantini MCA, Rubinger CPL, Faez R, Martins TS. Polyaniline inclusion into ordered mesoporous silica matrices: Synthesis, characterization and electrical transport mechanism. Microporous Mesoporous Mater. 2019;274:212-219.

Tarn D, Ashley CE, Xue M, Carnes EC, Zink JI, Brinker CJ. Mesoporous silica nanoparticle nanocarriers: biofunctionality and biocompatibility. Acc Chem Res. 2013;46(3):792-801.

Vieira CO, Grice JE, Roberts MS, Haridass IN, Duque MD, Lopes PS, Leite-Silva VR, Martins TS. ZnO:SBA-15 nanocomposites for potential use in sunscreen: preparation, properties, human skin penetration and toxicity. Skin Pharmacol Physiol. 2019;32(1):32-42.

Vinu A, Moria T, Ariga K. New families of mesoporous materials. Sci Technol Adv Mater. 2006;7(8):753-71.

Yamarik TA, Elmore AR. Final report of the safety assessment of urea. Int J Toxicol. 2005;24(3):1-56.

Yu J, Yang H, Li K, Lei J, Zhou L, Huang C. A novel application of nanohydroxyapatite/mesoporous silica biocomposite on treating dentin hypersensitivity: An in vitro study. J. Dent. 2016;50:21-29.

Zhao D, Feng J, Huo Q, Melosh N, Fredrickson GH, Chmelka BF, et al. Triblock copolymer syntheses of mesoporous silica with periodic 50 to 300A Pores. Science. 1998a;279(5350): 548-552.

Zhao D, Huo Q, Feng J, Chmelka BF, Stucky GD. Nonionic triblock and star diblock copolymer and oligomeric surfactant syntheses of highly ordered, hydrothermally stable, mesoporous silica structures. J Am Chem Soc. 1998b;120(24):6024-6036.

Received for publication on $14^{\text {th }}$ September 2017 Accepted for publication on $01^{\text {st }}$ April 2020 